Original Research Paper

\title{
Optimization of Conditions for Extraction of Pepsin-Soluble Collagen from Indonesian Local "Kacang" Goatskin by Response Surface Methodology
}

\author{
${ }^{1}$ Rina Wahyuningsih, ${ }^{1}$ Rusman, ${ }^{1}$ Nurliyani, ${ }^{1}$ Ambar Pertiwiningrum, \\ ${ }^{2}$ Abdul Rohman, ${ }^{1}$ Nanung Agus Fitriyanto and ${ }^{1 *}$ Yuny Erwanto \\ ${ }^{I}$ Department of Animal Products Technology, \\ Faculty of Animal Sciences, University of Gadjah Mada, Yogyakarta, Indonesia, 55281 \\ ${ }^{2}$ Department of Pharmaceutical Chemistry, \\ Faculty of Pharmacy, University of Gadjah Mada, Yogyakarta, Indonesia, 55281
}

Article history

Received: 10-03-2018

Revised: $16-03-2018$

Accepted: 10-05-2018

Corresponding Author:

Yuny Erwanto

Department of Animal

Products Technology, Faculty

of Animal Sciences, University

of Gadjah Mada, Yogyakarta,

Indonesia, 55281

Email: yunyer@ugm.ac.id

\begin{abstract}
Indonesian local "Kacang" goat is an animal species widely known by consumers over the world which possesses many health effects. Goatskin is one of body parts which has potential as collagen sources. The optimal conditions for collagen extraction were determined by response surface methodology in this study. Multiple response optimization designs were applied to evaluate the effects of two independent variables (curing time of $\mathrm{NaOH}$ and hydrolysis time) on the pepsin-soluble collagen yield of Indonesian local "Kacang" goatskin. Correlation analysis of the mathematical regression model indicated that quadratic polynomial model could be employed to optimize the extraction of pepsin-soluble collagen. The optimal conditions to obtain the highest yield of pepsin-soluble collagen was without curing $\mathrm{NaOH}$ and $24 \mathrm{~h}$ time of hydrolysis.
\end{abstract}

Keywords: Indonesia Local "Kacang" Goatskin, Pepsin-Soluble Collagen, Extraction, Response Surface Methodology

\section{Introduction}

Indonesian local "Kacang" goatskin has a high population in Indonesian and it is not too exposed as collagen sources especially as healthy products. Previous research has many reported the extraction of collagen sources from by-products of bovine, pig, chicken, rabbit and fish. However, there was no information about collagen extraction from goatskin. Collagen is a product which highly demanded and it used in the cosmetic, pharmaceutics and food industry. Collagen can be found in all animal parts but is mainly concentrated the skin and bone (Nakamura et al., 2003). Collagen is the product of an almost continuous repeating of the Gly$\mathrm{X}$-Y-sequence and the most abundant structural protein has formed as a unique triple helix by three almost identical polypeptide amino acids chain ( $\mathrm{Pal}$ et al., 2015; Gómez-Guillén et al., 2011).

Collagen extraction consist of two main steps, pretreatment of raw materials and extraction of collagen. Raw materials used for collagen preparation contains non-collagenous proteins, lipids, pigments, etc. It is important to remove impurities materials to increase the quality of the final extracted collagen (Regenstein and Zhou, 2007). $\mathrm{NaOH}$ is a widely used method to remove non-collagenous proteins and pigments ( $\mathrm{Pal}$ et al., 2015; Benjakul et al., 2012).

The extraction process of collagen usually use acid and pepsin method with different time and concentration. The study reported variant amounts of collagen from fish skin and rabbit skin. PSC from Grass Carp skin has yield 25.5 and $19.8 \%$ with optimal condition $72 \mathrm{~h}$ time of hydrolysis (Wang et al., 2014). Catla skin which extracted using pepsin has yield $69.53 \%$ with a time of hydrolysis was $48 \mathrm{~h}$ (Pal et al., 2015). PSC yield from rabbit skin with enzymatic treatment for $48 \mathrm{~h}$ was $71 \%$ (Pimentel-gonzález et al., 2015).

Therefore, skin as a material to prepare collagen is an exciting attempt at adding the value of the collagen. The raw material process (time of pretreatment) and extracted of collagen (time of hydrolysis) was important variables affecting the extractability of collagen especially collagen from 
Indonesian local "Kacang" goatskin. Response surface methodology is a statistical method used to quantitative data from an appropriate experimental design to determine or simultaneously solve multivariate equation (Triveni et al., 2001). The basic principle of response surface methodology is the evaluation of the relationship between predicted values the dependent variable and the conditions of dependent variables (Edwards and Jutan, 1997). The experimental methodology can generate a mathematical model and optimize the process levels (Baş and Boyaci, 2007; Yang et al., 2008). Publication of collagen extraction so far with response surface methodology is very limited. The objective of this work was to investigate the collagen extraction from local Indonesian "Kacang" goatskin which has a high population in Indonesian, mainly to the effects of above two variables on the yield of pepsin-soluble collagen by response surface methodology.

\section{Materials and Methods}

\section{Materials}

Indonesian local "Kacang" goatskin was obtained from local slaughterhouse with male sex and age in the range of one year. After being killed, the skins were washed, fleshing and unhairing to remove hair, fat, tissue and meat. Fresh skins were cleaned by washing with tap water, drained, cut into a small square of approximately $1 \mathrm{~cm}^{2}$ and stored at $-18^{\circ} \mathrm{C}$ until used for extraction.

\section{Chemical}

Sodium hydroxide and sodium chloride were purchased from Merck KgaA (Germany), acetic acid was purchased from Sigma-Aldrich (Germany) and pepsin from porcine gastric mucosa was purchased from Merck (Germany).

\section{Extraction by Pepsin Soluble Collagen}

Around one hundred grams of skin was thawed in room temperature for 1 hour and precisely weighed. The skin was mixed with $0.1 \mathrm{M} \mathrm{NaOH}$ at $4^{\circ} \mathrm{C}$ for $0 \mathrm{~h}, 24 \mathrm{~h}$ and $48 \mathrm{~h}$ ratio of $1: 10(\mathrm{w} / \mathrm{v})$ to remove non-collagenous proteins. The insoluble matter was extracted with $0.5 \mathrm{M}$ acetic acid containing $0.1 \%$ pepsin for 24,48 and $72 \mathrm{~h}$ at $38^{\circ} \mathrm{C}$. The extract was filtered with Whatman No.1 paper. The collagen was precipitated by adding $\mathrm{NaCl}$ at final concentration of $2.6 \mathrm{M}$. The pellet was collected by centrifuging at $7000 \mathrm{~g}$ for $30 \mathrm{~min}$ at $4^{\circ} \mathrm{C}$ and then redissolved in $0.5 \mathrm{M}$ acetic acid. The resulting solutions were dialyzed against $0.1 \mathrm{M}$ acetic acid for $24 \mathrm{~h}$ with a change of solution once per $3 \mathrm{~h}$ and finally, a change used distilled water sequentially. The collagen was obtained by freeze-drying. The experiment was conducted for 5 replications for each treatment.
Table 1: Experimental range and values of the independent variables in the multiple responses optimize design for pepsin-soluble collagen from Indonesian local "Kacang" goatskin

\begin{tabular}{lllll}
\hline & & \multicolumn{3}{l}{ Range and levels } \\
& & --------- \\
Independent variables (h) & Symbols & -1 & 0 & +1 \\
\hline Curing time of $\mathrm{NaOH}$ & $\mathrm{X} 1$ & 0 & 48 & 72 \\
Hydrolysis time & $\mathrm{X} 2$ & 24 & 48 & 72 \\
\hline
\end{tabular}

\section{Multiple Response Optimization Designs}

Response surface methodology was employed for experimental design, data analysis and model building with software Statgraphics Centurion version 15.2.11.0. The various responses optimize designs with two variables were used to determine the response pattern and then to establish a model. Two independent variables used in this study were curing time of $\mathrm{NaOH}$ (X1) and time of hydrolysis (X2) with three levels for each variable, while dependent variable was the yield of pepsin-soluble collagen. The ranges and center point values of two independent variables were based on the results of preliminary experiments in Table 1.

\section{Results}

\section{Effects of Curing Time of $\mathrm{NaOH}$ and Hydrolysis Time on the Yield of Pepsin-Soluble Collagen}

The effects of curing time of $\mathrm{NaOH}$ and hydrolysis time on the yield of pepsin-soluble collagen from Indonesian local "Kacang" goatskin was shown in Fig. 1. The yield of pepsin-soluble collagen was decreased with the extension time of treatment of $\mathrm{NaOH}$ and hydrolysis time with pepsin. Especially when the time was within the range treatment time of $\mathrm{NaOH}$ and hydrolysis time with pepsin $0 \mathrm{~h}$, the effect of amount yield of pepsinsoluble collagen. Process treatment time and hydrolysis time can be causes of collagen hydrolyzed.

\section{Model Fitting Data Analysis and Conditions for Optimum Responses}

All 27 experimental points were evaluated and the results of the dependent variable $(\mathrm{Y})$ for symbols and levels are shown in Table 2. This Table 3 shows each of the estimated effects and interactions. Also shown is the standard error of each of the effects, which measures their sampling error. Note also that the largest variance inflation factor (V.I.F.) equals 1.33333. For a perfectly orthogonal design, all of the factors would equal 1. Factors of 10 or larger are usually interpreted as indicating serious confounding amongst the effects.

This pane displays the regression equation which has been fitted to the data. The equation of the fitted model is: 


$$
\text { Yield }=4.61111-5.72222 X 1-28.2778 X 2
$$$$
+28.0667 X 1^{2}+2.25 X 1 X 2+25.0667 X 2^{2}
$$

where the values of the variables are specified in their original units.

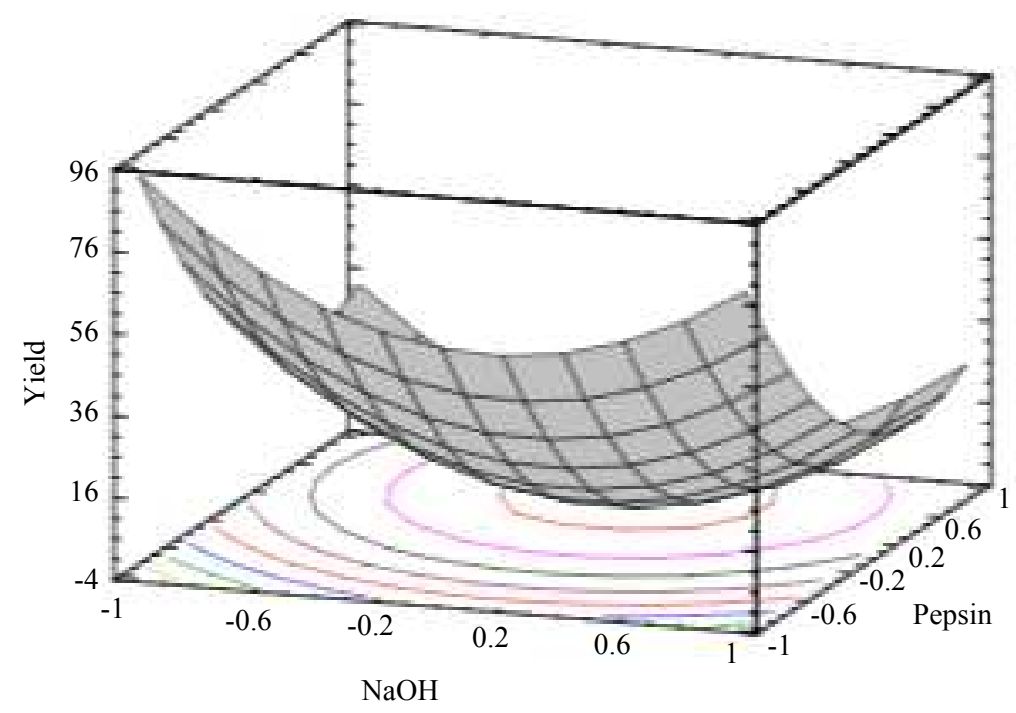

Fig. 1: Response surface plots for optimization of pepsin-soluble collagen from Indonesian local "Kacang" goatskin. NaOH (X1, curing time of $\mathrm{NaOH}, \mathrm{h})$, Pepsin (X2, hydrolysis time, h), Yield (Y, contents, \%)

Table 2: Multiple responses optimize design and the response for the yield of pepsin-soluble collagen from Indonesian local "Kacang" goatskin

\begin{tabular}{|c|c|c|c|}
\hline \multirow[b]{2}{*}{ Experiment } & \multicolumn{2}{|l|}{ Coded levels } & \multirow{2}{*}{$\begin{array}{l}\text { Response } \\
\text { Yield (Y) of pepsin-soluble } \\
\text { collagen (\%) }\end{array}$} \\
\hline & $\begin{array}{l}\mathrm{X} 1 \\
\text { Curing time of } \mathrm{NaOH}(\mathrm{h})\end{array}$ & $\begin{array}{l}\text { X2 } \\
\text { Hydrolysis time (h) }\end{array}$ & \\
\hline 1 & -1 & -1 & 58.00 \\
\hline 2 & -1 & 0 & 31.00 \\
\hline 3 & -1 & +1 & 17.00 \\
\hline 4 & -1 & -1 & 133.00 \\
\hline 5 & -1 & 0 & 46.00 \\
\hline 6 & -1 & +1 & 15.00 \\
\hline 7 & -1 & -1 & 156.00 \\
\hline 8 & -1 & 0 & 10.00 \\
\hline 9 & -1 & +1 & 9.00 \\
\hline 10 & 0 & -1 & 14.00 \\
\hline 11 & 0 & 0 & 9.77 \\
\hline 12 & 0 & +1 & 45.00 \\
\hline 13 & 0 & -1 & 12.00 \\
\hline 14 & 0 & 0 & 15.71 \\
\hline 15 & 0 & +1 & 33.00 \\
\hline 16 & 0 & -1 & 13.00 \\
\hline 17 & 0 & 0 & 12.42 \\
\hline 18 & 0 & +1 & 37.00 \\
\hline 19 & +1 & -1 & 146.00 \\
\hline 20 & +1 & 0 & 23.00 \\
\hline 21 & +1 & +1 & 10.00 \\
\hline 22 & +1 & -1 & 112.00 \\
\hline 23 & +1 & 0 & 17.00 \\
\hline 24 & +1 & +1 & 9.00 \\
\hline 25 & +1 & -1 & 46.00 \\
\hline 26 & +1 & 0 & 24.00 \\
\hline 27 & +1 & +1 & 6.00 \\
\hline
\end{tabular}


Table 3: Estimated coefficients of the fitted quadratic polynomial equation for the response of Y (contents, \%) based total error of degree of freedom

\begin{tabular}{lrll}
\hline Effect & Estimate & Standard error & V.I.F \\
\hline Average & 4.61111 & 15.9904 & 1.00000 \\
X1 & -11.44440 & 17.5166 & 1.00000 \\
X2 & -56.55560 & 17.5166 & 1.00000 \\
X1X1 & 56.13330 & 30.3396 & 1.00000 \\
X1X2 & 4.50000 & 21.4533 & 1.00000 \\
X2X2 & 50.13330 & 30.3396 & 1.33333 \\
Block & 3.86889 & 20.2264 & 1.33333 \\
Block & -2.41778 & 20.2264 & \\
\hline
\end{tabular}

$\mathrm{X} 1$ : Curing time of $\mathrm{NaOH}(\mathrm{h}), \mathrm{X} 2$ : Hydrolysis time (h)

Table 4: Analysis of variance for the response surface quadratic model of the yield of pepsin-soluble collagen from Indonesia local "Kacang" goatskin

\begin{tabular}{lrrrr}
\hline Source & Sum of squares & Df & Mean square & F-ratio \\
\hline X1 & 589.3890 & 1 & 589.3890 & 0.43 \\
X2 & 14393.4000 & 1 & 14393.4000 & 0.5214 \\
X1X1 & 4726.4300 & 1 & 4726.4300 & 0.0044 \\
X1X2 & 60.7500 & 1 & 60.7500 & 0.42 \\
X2X2 & 3770.0300 & 1 & 3770.0300 & 0.0799 \\
Blocks & 51.5693 & 2 & 25.7846 & 0.04 \\
Total error & 26233.9000 & 19 & 1380.7300 & 0.73 \\
Total (corr.) & 49825.5000 & 26 & & 0.9815 \\
X1:Curing & & &
\end{tabular}

$\mathrm{X} 1$ : Curing time of $\mathrm{NaOH}(\mathrm{h}), \mathrm{X} 2$ : Hydrolysis time (h)

The ANOVA (Table 4) partitions the variability in yield into separate pieces for each of the effects. It then tests the statistical significance of each effect by comparing the mean square against an estimate of the experimental error. In this case, 1 effects have P-values less than 0.05 , indicating that it was significantly different from zero at the $95.0 \%$ confidence level. The R-Squared statistic indicates that the model as fitted explains $47.3484 \%$ of the variability in Yield.

The adjusted R-squared statistic, which is more suitable for comparing models with different numbers of independent variables is $34.8123 \%$. Standard error of the estimate shows was the standard deviation of the residuals to be 37.1582. Mean Absolute Error (MAE) of 25.5298 is the average value of the residuals. P-value is greater than $5.0 \%$; there is no indication of serial autocorrelation in the residuals at the $5.0 \%$ significance level. The predicted content of the dependent variable (Y, contents) was $93.9944 \%$ from calculations using the model equation derived from the above optimal conditions. This study the optimal conditions to obtain the highest yield of pepsin-soluble collagen was curing time of $\mathrm{NaOH} 0 \mathrm{~h}$ and hydrolysis time $24 \mathrm{~h}$.

\section{Discussion}

Collagen extraction consists of two main steps, pretreatment of raw materials and extraction of collagen. The purpose of pretreatment is performed to facilitate the contaminant removal (non-collagenous proteins, fats, pigments, hairs, meat and so on) and maximum collagen extraction (Pal and Suresh, 2016). $\mathrm{NaOH}$ is alkaline pretreatment to remove the non-collagenous proteins and pigments (Pal et al., 2015; Benjakul et al., 2012). In this study was a show of pretreatment with $\mathrm{NaOH}$ can affect the yield of collagen. Curing of $\mathrm{NaOH}$ in this study not successful significant because of the longer curing time then, the less of the yield of collagen produces. Extension of $\mathrm{NaOH}$ of raw material from Indonesian local "Kacang" goatskin can effect of collagen remove and causes of decreasing the yield of collagen produces.

Previous research founded acid soluble collagen from Black tilapia has yield production was $5.97 \%$ with 0.75 $\mathrm{M}$ of acetic acid lower than yield production of PSC (Sahubawa and Putra, 2011). Extraction of collagen using enzymatic extraction process has been developed to maximize of collagen yield. Various enzymes to extraction of collagen such as pepsin, trypsin and collagenase have been used to maximize the yield of collagen (Benjakul et al., 2012; Regenstein and Zhou, 2007). The enzyme used in the most to the extraction of collagen is pepsin and can be used either in combination with acetic acid or alone after initial extracting of collagen within acetic acid. This study showed that use of limited pepsin to extraction of collagen can be increased the yield of collagen (Liang et al., 2014; Wang et al., 2014; Pal et al., 2015; Mahboob, 2015; Chuaychan et al., 2015; Jeevithan et al., 2014; Veeruraj et al., 2013; Tamilmozhi et al., 2013). Potential method extraction of collagen with a limited of pepsin such as pepsin can hydrolyse the non-collagenous proteins and also can be easily removed using salt presipitation and dialysis to improve purity of collagen, pepsin can hydrolyse the 
telopeptides of collagen that may be resulting in improvement of the extraction efficiency and pepsin can be significant effect problem in food and pharmaceutical applications because pepsin digestion may reduce the antigenicity caused by telopeptide in collagen (Duan et al., 2009; Matmaroh et al., 2011; Benjakul et al., 2012; Wang et al., 2014). The based on before study showed that the addition of $\mathrm{NaOH}$ as a pretreatment before extraction of collagen could great affect the yield of collagen produces because, without the addition of $\mathrm{NaOH}$, pepsin was can to hydrolysis non-collagenous proteins.

The optimal predicted yield of pepsin-soluble collagen from Indonesia local "Kacang" goatskin in this study was $93.9944 \%$ with optimum condition of treatment time of $\mathrm{NaOH} 0 \mathrm{~h}$ and hydrolysis time $24 \mathrm{~h}$. The efficiency of extraction was mass transfer rate of analyze the matrix plays (Bartle et al., 1991). The mass transfer rate is controlled by the diffusion process which is time-dependent and the recovery of analyzing keeps increasing along with the extension of time (Wang et al., 2008). This result indicated that there was abundant collagen in Indonesian local "Kacang” goatskin.

\section{Conclusion}

On the basis of this result, in conclusion this study of the two variables (curing time of $\mathrm{NaOH}$ and hydrolysis time) showed a significant effect in the extraction of pepsin-soluble collagen. The optimal conditions to obtain the highest yield of pepsin-soluble collagen is without curing of $\mathrm{NaOH}(\mathrm{NaOH} 0 \mathrm{~h})$ and hydrolysis time of pepsin $24 \mathrm{~h}$. The predicted yield of pepsinsoluble collagen was $93.9944 \%$ which was in agreement with the actual value $(p<0.05)$ indicating that it was significantly different from zero at the $95.0 \%$ confidence level. The results of this study were helpful for the production of pepsin-soluble collagen from Indonesian local "Kacang" goatskin.

\section{Acknowledgement}

This research work was supported by DIKTI Ministry of Research, Technology and Higher Education Indonesia with contract No: 4586/UN1-III/LT/DIT-LIT/2016.

\section{Funding Information}

The preparation of research and manuscript was supported by DIKTI Ministry of Research, Technology and Higher Education Indonesia

\section{Author's Contributions}

Rina Wahyuningsih: Record the data of the experiment in the field, analysis of the data and contributes to the writing of the article.
Rusman, Nurliyani, Ambar Pertiwiningrum, Abdul Rohman and Nanung Agus Fitriyanto: Reviewing it critical for significant intellectual content.

Yuny Erwanto: Research idea proposes, experiment supervision and final approval of the version to be submitted and any revised version.

\section{Ethics}

All of the authors confirm that this article is original and no ethical issues are concerned with the present article.

\section{References}

Baş, D. and I.H. Boyaci, 2007. Modeling and optimization I: Usability of response surface methodology. J. Food Eng., 78: 836-845.

DOI: $10.1016 /$ j.jfoodeng.2005.11.024

Bartle, K.D., T. Boddington, A.A. Clifford, N.J. Cotton and C.J. Dowle, 1991. Supercritical fluid extraction and chromatography for the determination of oligomers in poly (ethylene terephthalate) films. Analytical Chem., 63: 2371-2377. DOI: $10.1021 / \mathrm{ac00020a031}$

Benjakul, S., S. Nalinanon and F. Shahidi, 2012. Fish Collagen. In: Food Biochemistry and Food Processing, Simpson, B.K. (Ed.), Wiley Online Library, ISBN-10: 1118308050, pp: 365-387.

Chuaychan, S., S. Benjakul and H. Kishimura, 2015. Characteristics of acid-and pepsin-soluble collagens from scale of seabass (Lates calcarifer). LWT-Food Sci. Technol., 63: 71-76.

DOI: $10.1016 /$ j.lwt.2015.03.002

Duan, R., J. Zhang, X. Du, X. Yao and K. Konno, 2009. Properties of collagen from skin, scale and bone of carp (Cyprinus Carpio). Food Chem., 112: 702-706. DOI: 10.1016/j.foodchem.2008.06.020

Edwards, I.M. and A. Jutan, 1997. Optimization and control using response surface methods. Comput. Chem. Eng., 21: 441-53. DOI: 10.1016/S00981354(96)00007-5

Gómez-Guillén, M.C., B. Giménez, M.E. al LópezCaballero and M.P. Montero, 2011. Functional and bioactive properties of collagen and gelatin from alternative sources: A review. Food Hydrocolloids, 25: 1813-1827.

DOI: 10.1016/j.foodhyd.2011.02.007

Jeevithan, E., W. Wu, W. Nanping, H. Lan and B. Bao, 2014. Isolation, purification and characterization of pepsin soluble collagen isolated from silvertip shark (Carcharhinus albimarginatus) skeletal and head bone. Process Biochem., 49: 1767-1777. DOI: $10.1016 /$ j.procbio.2014.06.011 
Liang, Q., L. Wang, W. Sun, Z. Wang and J. Xu et al., 2014. Isolation and characterization of collagen from the cartilage of Amur sturgeon (Acipenser schrenckii). Process Biochem., 49: 318-323.

DOI: 10.1016/j.procbio.2013.12.003

Mahboob, S., 2015. Isolation and characterization of collagen from fish waste material-skin, scales and fins of Catla catla and Cirrhinus mrigala. J. Food Sci. Technol., 52: 4296-4305.

DOI: $10.1007 / \mathrm{s} 13197-014-1520-6$

Matmaroh, K., S. Benjakul, T. Prodpran, A.B. Encarnacion and H. Kishimura, 2011. Characteristics of acid soluble collagen and pepsin soluble collagen from scale of spotted golden goatfish (Parupeneus heptacanthus). Food Chem., 129: $1179-1186$.

DOI: 10.1016/j.foodchem.2011.05.099

Nakamura, Y.N., H. Iwamoto, Y. Ono, N. Shiba and S. Nishimura et al., 2003. Relationship among collagen amount, distribution and architecture in the $\mathrm{M}$. Longissimus Thoracis and M. Pectoralis Profundus from pigs. Meat Sci., 64: 43-50. PMID: 22062661

Pal, G.K., T. Nidheesh and P.V. Suresh, 2015. Comparative study on characteristics and in vitro fibril formation ability of acid and pepsin soluble collagen from the skin of catla (Catla Catla) and rohu (Labeo Rohita). Food Res. Int., 76: 804-812. DOI: 10.1016/j.foodres.2015.07.018

Pal, G.K. and P.V. Suresh, 2016. Sustainable valorisation of seafood by-products: Recovery of collagen and development of collagen-based novel functional food ingredients. Innovative Food Sci. Emerg. Technol., 37: 201-215.

DOI: $10.1016 /$ j.ifset.2016.03.015

Pimentel-González, D.J., R.G. Campos-Montiel, M.A. Martínez-Ortiz, A.D. Hernández-Fuentes et al., 2015. Extraction and characterization of collagen from rabbit skin: Partial characterization. J. Food, 13: 253-258. DOI: 10.1080/19476337.2014.946451
Regenstein, J.M. and P. Zhou, 2007. Collagen and Gelatin from Marine by-Products. In: Maximising the Value of Marine by-Products, Woodhead Publishing Limited Cambridge, pp: 279-303.

Sahubawa, Latif and A.B. Naro Putra, 2011. Effect of Acetic Acid and Extraction Time on Collagen Quality of Black Tilapia Fish Skin. J. Teknosains, 1: 16-25.

Tamilmozhi, S., A. Veeruraj and M. Arumugam, 2013. Isolation and characterization of acid and pepsin-solubilized collagen from the skin of sailfish (Istiophorus platypterus). Food Res. Int., 54: 1499-1505.

DOI: $10.1016 /$ j.foodres.2013.10.002

Triveni, R., T.R. Shamala and N.K. Rastogi, 2001. Optimised production and utilisation of exopolysaccharide from Agrobacterium radiobacter. Process Biochem., 36: 787-795. DOI: 10.1016/S0032-9592(00)00279-X

Veeruraj, A., M. Arumugam and T. Balasubramanian, 2013. Isolation and characterization of thermostable collagen from the marine eel-fish (Evenchelys macrura). Process Biochem., 48: 1592-1602. DOI: $10.1016 /$ j.procbio.2013.07.011

Wang, L., Q. Liang, T. Chen, Z. Wang and J. Xu et al., 2014. Characterization of collagen from the skin of amur sturgeon (Acipenser schrenckii). Food Hydrocolloids, 38: 104-109.

DOI: 10.1016/j.foodhyd.2013.12.002

Wang, L., B. Yang, X. Du, Y. Yang and J. Liu, 2008. Optimization of conditions for extraction of acidsoluble collagen from grass carp (Ctenopharyngodon idella) by response surface methodology. Innovative Food Sci. Emerg. Technol., 9: 604-607. DOI: $10.1016 /$ j.ifset.2008.03.001

Yang, L., K.O. der Werf, C.F.C. Fitié, M.L. Bennink and P.J. Dijkstra et al., 2008. Mechanical properties of native and cross-linked type I collagen fibrils. Biophys. J., 94: 2204-2211. DOI: 10.1529/biophysj.107.111013 